\title{
The Interrelationship between number of Symptoms and Patients' Request for General and Routine Laboratory Tests.
}

\author{
Adil Alharthi ${ }^{1 *}$, Muhammad Nadeem Khan ${ }^{2}$, Waqas Farooq ${ }^{3}$, Samsam Mushtaq ${ }^{4}$, and Ahmed Rasheed \\ ${ }^{1}$ Adil Alharthi, MD, Author, KFAFH Jeddah, KSA. \\ ${ }^{2}$ Muhammad Nadeem Khan, MD, co-author, VAMC Chillicothe Ohio, USA. \\ ${ }^{3}$ Waqas Farooq, MD, co-author, KFAFH Jeddah, KSA. \\ ${ }^{4}$ Samsam Mushtaq, MD, co-author, KFAFH Jeddah, KSA. \\ ${ }^{5}$ Ahmed Rasheed, MD, co-author, KFAFH Jeddah, KSA.
}

*Corresponding author: Adil Alharthi, KFAFH Jeddah, KSA.

Received date: April 15, 2020; Accepted date: April 24, 2020; Published date: April 29, 2020

Citation: Alharthi A., Muhammad N. Khan., Farooq W., Mushtaq S., and Rasheed A., (2020) The interrelationship between number of symptoms and patients' request for general and routine laboratory tests. J. Archives of Medical Case Reports and Case Study. 3(1); DOI:10.31579/2692-9392/010

Copyright: () 2020 Adil Alharthi, This is an open access article distributed under the Creative Commons Attribution License, which permits unrestricted use, distribution, and reproduction in any medium, provided the original work is properly cited.

\section{Abstract}

The overuse of laboratory tests is widely prevalent in hospital settings which increases healthcare costs. Although there is previous research on this subject, little is known about the relationship between symptoms and patient requests. Our study aims to identify if adult patients with multiple symptoms ask for general investigations more than single symptom patients?

Keywords: overuse of investigations; lab test; patient request of investigation; patient education; physician education.

\section{Abbreviations: pts $=$ patients}

\section{Introduction:}

In health care, one method of disease diagnosis is through laboratory tests. Nowadays the overuse of laboratory tests is widely prevalent in hospital settings which increases healthcare costs. It has been estimated that in the United States annual costs for these services are 3,000,000,000 dollars [6]. The total accumulated cost of these tests is high and falsepositive results are frequent. Such results may cause anxiety and lead to unnecessary referrals for additional testing and investigation [1]. Other studies showed that unnecessary testing can lead to adverse effects eg, iatrogenic anemia, poor sleep quality, the risk for infections and increased cost of care [3].

Inappropriate testing may cause unnecessary patient discomfort, entails the risk of generating false-positive results, leads to overloading of the diagnostic services, wastes valuable healthcare resources and is associated with other inefficiencies in healthcare delivery, undermining the quality of health services [7].

High rates of unnecessary laboratory tests have been recorded in pediatric, internal medicine, surgical and even emergency departments, as well as in intensive care units, implying that redundant ordering of tests is a universal phenomenon in the hospital setting [7, 9].

Even the utilization of high-technology and high-cost diagnostic imaging has increased substantially over the past decades. This growth can be attributed to various factors such as aging populations, advances in technology, availability of the technology, and an increasing number of specialists [5].

There are numerous reasons for this increase which is related to doctors, patients, society, and, advances in technology and the medical system. Several studies have been conducted to examine the reasons. Little et al. 2009 examined the effect of patient pressure on doctors to provide prescriptions and referrals. Their study showed that $46 \%$ of doctors felt that their referral was unwarranted but did fulfill the patient's request. The most influential factor was perceived as patient pressure. In other study patient expectations and fear of legal action were other influential reasons [5[. Doctors reasons for ordering excessive tests were defensive behavior, fear, uncertainty, lack of experience, the importance of using protocols and guidelines, inadequate educational feedback, and lack of information about the cost of examinations $[4,7]$.

Studies showed that educated patients request more tests for disease prevention. The types of tests that are usually requested were imaging scans, electrocardiograms, and blood tests such as blood counts, glucose, renal function tests, urinalysis, liver function tests. The reason for the request was $60 \%$ for symptoms, and $25 \%$ for disease prevention. Furthermore, one study showed that the decision to do baseline tests was influenced by presence of risk factors $(86 \%)$, age $(61 \%)$, positive family history (59\%), patient request (24\%), and sex (20\%).

Literature showed that senior doctors ordered more laboratory tests, but the percentage of avoidable tests requested by junior trainees was higher [7]. 
One qualitative study was conducted in Holland in 2006 found that patients perceived test results as proof for good health and considered blood tests as a useful screening tool for disorders. (Wisely, 2017).

Although there are many kinds of research on these subjects, little is known about the relationship between symptoms and patient requests. So, our study aimed to identify if adult patients with multiple symptoms ask for general investigations more than single symptom patients.

\section{Materials and methods:}

A descriptive cross-sectional study was conducted from October to November 2019 in the general medicine clinic of KFAFH in Jeddah. All patients presenting to this Clinic were included.

Exclusion Criteria were: 1- Patients seen more than once during the study duration. 2-Patients following in the Clinic for Medication renewal only i.e. without symptoms and not asking for investigations. We distributed a data sheet to the doctors covering the general medicine clinic and trained them to complete the questionnaire. After an initial test period of 2 days, we reviewed their data, discussed with them the challenges and difficulties, and then started the study after appropriate modifications. The form contained a series of tick boxes, which listed the patient's number of symptoms and whether the patient asked for general investigations or asked for specific investigations. The patient's personal information was not collected and not used in the study. The breakdown of the number of the study population was as follows. All patients presenting to the clinic $=715$. Patients excluded from this study for drug renewal follow up with no other symptoms $=237$ Patients excluded for presenting to the clinic more the once in the study duration $=72$ Remaining Patient that were included in this study $=406$.

\section{Results and Discussion:}

\section{Results:}

Out of the 406 patients who were included in the study, 160 (39.4\%) asked for general investigations. Subgroup analysis was as follows: $\square 315$ patients had symptoms and out of these $123(39.04 \%)$ asked for General Investigations. $\square 115$ patients had a single symptom and out of these 33 (28.69\%) asked for General Investigations. $\square 200$ patients had multiple symptoms and out of these 90 (45\%) asked for General Investigations (Figure 2).

A further break down of these is as follows: $\square 78$ patients had two symptoms and out of these $34(43.58 \%)$ asked for General Investigations. $\square 122$ patients had three or more symptoms and out of these 56 (45.9\%) asked for General Investigations (Figure 3).

An additional finding was that 91 patients had no symptoms and out of these $37(40.65 \%)$ asked for General investigations (Figure 1).

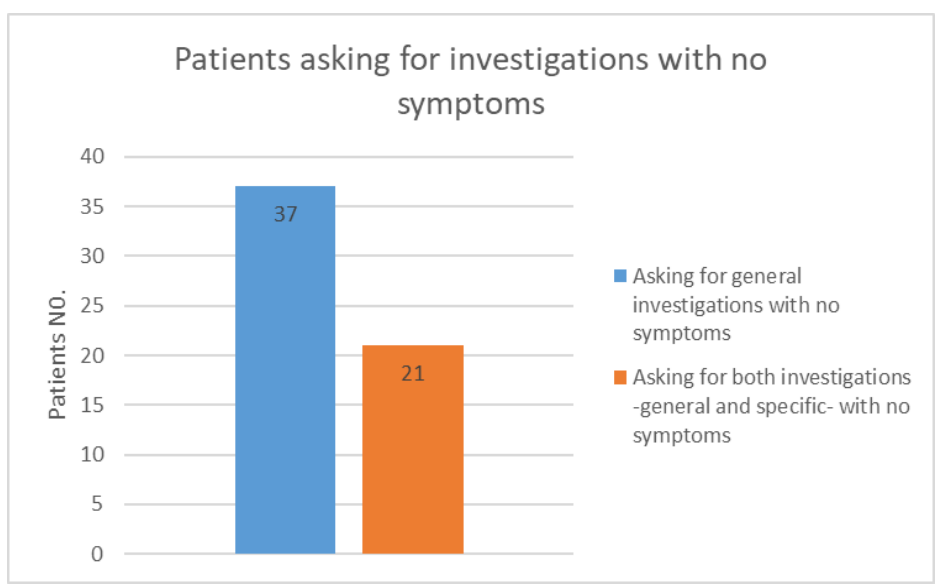

Figure Legend 1: Patients asking for investigations with no symptoms.
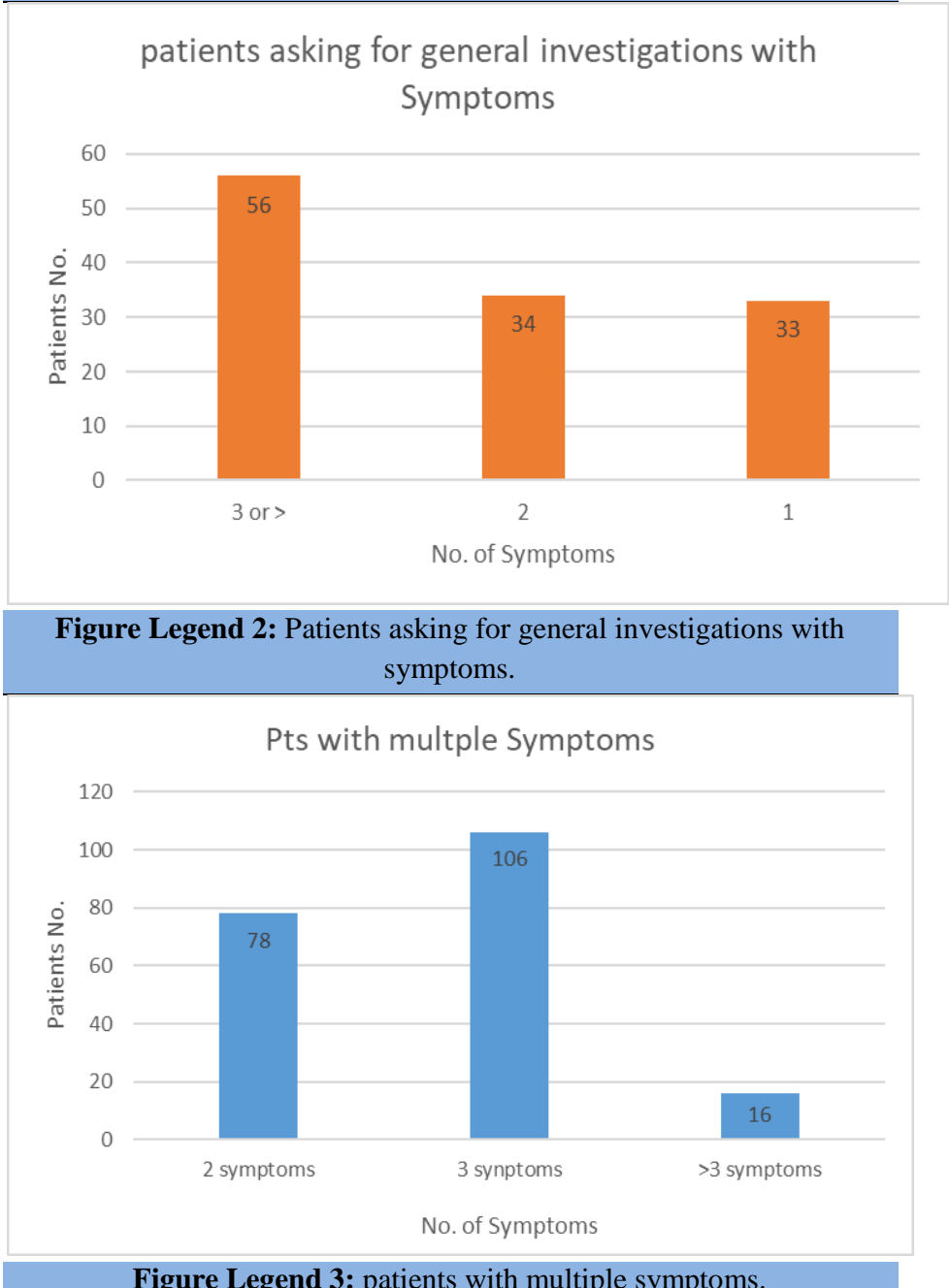

Figure Legend 3: patients with multiple symptoms. 


\section{Discussion:}

Our study suggests that there was a trend of a greater number of patients asking for general investigations as the number of symptoms increased among those patients who had symptoms. The greatest increase was from patients with one symptom to two symptoms $(28.69 \%$ vs. $43.58 \%)$ and marginally more from two to three or more symptoms $(43.58 \%$ vs. $45.9 \%)$.

Several previous studies have also shown an overuse of laboratory examinations in routine hospital practice [7]. Indicated that almost $68 \%$ of these tests commonly ordered in an academic internal medicine ward were unnecessary. They concluded that repeated assessment and continuous education of doctors result in decreasing the redundant ordering of tests in the hospital setting [7].

Also, [6] in their study identified that $65 \%$ of the patients requested unnecessary examinations, $25 \%$ did not request the tests that was required, and only $10 \%$ of the patients requested tests pertaining to the reference criteria. They highlighted the importance of adherence to the reference criteria which could prevent major expenditures [6].

There was an additional unexpected finding that was not part of the original study aim, that asymptomatic patient asked for General Investigations compared to those with any symptoms as a group $(40.65 \%$ vs. $39.04 \%$ ), though less so than those with two or three symptoms (40.65\% vs. $45 \%)$.

This result is similar to other results in other countries. One survey found that $61.6 \%$ of doctors think that unnecessary testing is a very serious problem in the New Zealand health system. Also, a similar survey in the USA found that $73 \%$ of physicians said that the frequency of unnecessary tests is a very serious problem in the health care system. This is also consistent with the finding of another study in the US, which found that primary care physicians feel more pressure from patients for tests and procedures [6].

Literature suggested that evidence-based guidelines and education of physicians for these tests are needed. Reducing the performance of routine tests have caused considerable savings without any effect on the quality of care $[3,8]$.

Furthermore, choose wisely association 2017 highlighted that doctors need to understand patients' motivations so they can communicate more effectively with their patients. Besides, patient education may help to minimize the harm and costs of unnecessary tests [10].

Also, Corson et al., 2015 highlighted that a community-based hospitalist program can be effective in reducing healthcare costs without affecting the quality of care. Their program did not affect the length of hospitalization, mortality, or readmission [10].

\section{Study Limitations:}

Though we tried our best, there could have been a source of error if there was a communication barrier between non-Arabic speaking clinic doctors and the Arabic speaking patients. The study was performed in October and November and may not reflect seasonal variations. Since these patients may have been seen after discharge from the hospital or referred from the family medicine clinic, they may have already had general investigations and may have not asked for them. We suggest further studies to compare the demographic, clinical and laboratory characteristics of patients asking for general investigations.

\section{Conclusion:}

Our study showed that adult patients with multiple symptoms ask for general investigation more than single symptom patients. It also shows that the overuse of laboratory tests is widely prevalent in hospital settings. The frequency of unnecessary tests ordered can be decreased by educating physicians and patients by making them aware of the indications for labs and their cost.

\section{References}

1. COHEN, O., KAHAN, E., ZALEWSKI, S. \& KITAI, E. (1999). Medical Investigations Requested by Patients: How Do Primary Care Physicians React? Fam Med, 31, 426-431.

2. CORSON, A. H., FAN, V. S., WHITE, T., SULLIVAN, S. D., ASAKURA, K., MYINT, M. \&

a. DALE,C.R. (2015).

Amultifacetedhospitalistqualityimprovementinterve ntion:

b. Decreased frequency of common labs. J Hosp Med, 10, 390-3905.

3. FAISAL, A., ANDRES, K., RIND, J. A. K., DAS, A., ALTER, D. et al. (2018). Reducing the number of unnecessary routine laboratory tests through education of internal medicine residents. Postgrad Med J, 94, 716-719.

4. HOUBEN, P. H., WINKENS, R. A., VAN DER WEIJDEN, T., VOSSEN, R. C., NAUS, A. J. \& GROL, R. P. (2010) Reasons for ordering laboratory tests and relationship with frequency of abnormal results. Scand J Prim Health Care, 28, 18-23.

5. LYSDAHL, K. B. \& HOFMANN, B. M. (2009). What causes increasing and unnecessary use of radiological investigations? A survey of radiologists' perceptions. BMC Health Serv Res, 9, 155.

6. MATA-MIRANDAA, M. P., CANO-MATUS, N., RODRIGUEZ-MURRIETA, M., GUARNEROS-ZAPATAC, I. \& ORTIZ, M. (2016). Unnecessary routine laboratory tests in patients referred for surgical services. CIRUGÍA $y$ CIRUJANOS, 84, 121-126.

7. MIYAKIS, S., KARAMANOF, G., LIONTOS, M. \& MOUNTOKALAKIS, T. D. (2006). Factors contributing to inappropriate ordering of tests in an academic medical department and the effect of an educational feedback strategy. Postgrad Med J, 82, 823-829.

8. NAKAR, S., VINKER, S., NEUMAN, S., KITAI, E. \& YAPHE, J. (2002). Baseline tests or screening: what tests do family physicians order routinely on their healthy patients? $J$ Med Screen 9, 133-134.

9. VAN DER HORST, A., VAN DE WIJNGAART, D. J., SCHERRENBURG, J., VAN DIJK, N. \& JANSSENS, P. M. W. (2017). Practical motives are prominent in test-ordering in the Emergency Department. Clin Chem Lab Med, 55, 15231529.

10. WISELY, C. (2017). SURVEY OF DOCTORS' PRACTICE REGARDING UNNECESSARY TESTS, TREATMENTS AND PROCEDURES IN NEW ZEALAND [Online]. 
This work is licensed under Creative Commons Attribution 4.0 License

To Submit Your Article Click Here: Submit Article

DOI:10.31579/2692-9392/010

Ready to submit your research? Choose Auctores and benefit from:

* fast, convenient online submission

* rigorous peer review by experienced research in your field

* rapid publication on acceptance

* authors retain copyrights

* unique DOI for all articles

* immediate, unrestricted online access

At Auctores, research is always in progress.

Learn more www.auctoresonline.org/journals/archives-of-medical-casereports-and-case-study 